\title{
Comparison of two methods to explore consumer preferences for cottage cheese
}

\author{
S. L. Drake, K. Lopetcharat, and M. A. Drake ${ }^{1}$ \\ Department of Food, Bioprocessing, and Nutritional Sciences, Southeast Dairy Foods Research Center, North Carolina State University, \\ Raleigh 27695-7624
}

\begin{abstract}
In the past 2 decades, total sales of cottage cheese have declined $17 \%$ despite increases in sales for low-fat cottage cheese. There are no recent published studies investigating consumer preferences for cottage cheese. This study was conducted to identify and define sensory characteristics of commercial cottage cheese and to compare 2 approaches for characterizing consumer preferences: traditional preference mapping and a new composite qualitative approach, qualitative multivariate analysis (QMA). A sensory language was identified to document the sensory properties (visual, flavor, and texture) of cottage cheeses. Twenty-six commercial cottage cheeses with variable fat contents $(4,2,1$, and $0 \%$ fat) were evaluated by trained panelists using the sensory language. Eight representative cottage cheeses were selected for consumer acceptance testing $(\mathrm{n}=110)$ and QMA with consumer home usage testing $(\mathrm{n}=12)$, followed by internal and external preference mapping to identify key drivers. Principal component analysis of descriptive data indicated that cottage cheeses were primarily differentiated by cooked, milkfat, diacetyl, and acetaldehyde flavors and salty taste, and by firmness, smoothness, tackiness, curd size, and adhesiveness texture attributes. Similar drivers of liking (diacetyl and milkfat flavors, smooth texture, and mouthcoating) were identified by both consumer research techniques. However, the QMA technique identified controversial distinctions among the cottage cheeses and the influence of brand and pricing. These results can be used by processors to promote cottage cheese sales.
\end{abstract}

Key words: cottage cheese, preference mapping, qualitative multivariate analysis, home usage test

\section{INTRODUCTION}

Cottage cheese is defined in the United States as a "soft uncured cheese prepared by mixing cottage cheese

Received May 17, 2009.

Accepted September 1, 2009.

${ }^{1}$ Corresponding author: mdrake@unity.ncsu.edu dry curd with a creaming mixture" (21CFR 133.128; Code of Federal Regulations, 2004). Cottage cheese curds can be manufactured by the acid coagulation of skim milk, typically through starter culture activity, although milk may also be directly acidified. Fifteen years ago, it was common for cottage cheese dry curd to be manufactured by direct acidification with food-grade acidulants. Today, starter culture fermentation and direct acidification are both used (Brandon Nelson, Daisy Brand LLC, Garland, TX; personal communication). The creaming mixture, or free dressing, is traditionally made from cream, milk, and salt.

There has been a decrease in cottage cheeses sales. Production of full-fat, also called creamed, cottage cheese decreased to 167 million kilograms in $2006 \mathrm{com}-$ pared with 294.1 million kilograms in 1988 (Anonymous, 2006). Low-fat cottage cheese production increased from 132.2 million kilograms in 1988 to 185.4 million kilograms in 2006 (Anonymous, 2006). Some possible reasons for the decrease in overall consumption could be image-related or could be because of changes in diet and consumption behavior. For example, cottage cheese has an image problem because it is regarded as a bland and boring product for older people (Reiter, 1993). The California Milk Advisory Board conducted a consumer focus group and found that consumers rated cottage cheese as boring and lacking flavor (as reported in Antinone et al., 1994). Furthermore, cottage cheese has been positioned as a diet food for decades and people continue to associate cottage cheese with dieting (Reiter, 1993). Some other problems with cottage cheese are inconsistency in product quality (flavor and texture), decreased curd-to-dressing ratio, inconvenient packaging, and years of neglect in the marketplace (Honer, 1990; Reiter, 1993; Bodyfelt and Potter, 2009).

Specific attention to some of these issues has been fruitful. Sales in the cottage cheese category began to recover in 1999 with the introduction of cottage cheese packaged with fruit purée (Berry, 1999). Another idea that attempted to revitalize the cottage cheese category was targeting the prebiotic and probiotic market segment. Several products have been launched in this area (Ramirez, 2007). However, promoting and attracting 
new and younger consumers must be part of a longterm plan for this product category (Ramirez, 2007).

Cottage cheese has a mild flavor that is attributed to milkfat, other milk components, and starter bacteria or acidulant (Walstra et al., 1999; Bodyfelt and Potter, 2009). According to ideal standards for cultured dairy products, the ideal creamed cottage cheese (fullfat) flavor should be fresh, pleasant, and clean, with slight acidity and mild diacetyl flavor with no aftertaste (Bodyfelt and Potter, 2009). Ideal cottage cheese curds should be uniform, and with a meaty texture without being too firm, rubbery, or tough (Bodyfelt and Potter, 2009).

Few studies have addressed sensory properties or consumer perception of this product. Antinone et al. (1994) reported that consumers wanted a higher diacetyl concentration in low-fat (4 ppm) cottage cheese compared with full-fat (1 ppm) cottage cheese. Demott et al. (1984) evaluated application of salt substitutes in cottage cheese and consumer responses. Although there are ideal quality standards for cottage cheese, previous studies with other dairy products such as Cheddar cheese and butter have established that consumers are often diverse and that what is considered a defect or desirable by ideal standards is not necessarily the case with consumers (Singh et al., 2003; Young et al., 2004; Krause et al., 2007; Drake et al., 2008). To our knowledge, very few published studies have evaluated consumer preference and perception of cottage cheese.

Traditional preference mapping involves application of quantitative consumer testing with a large number of consumers (generally $\geq 100$ ) with or without trained panel profiles of products to identify key drivers of like or dislike for a product category (Meilgaard et al., 1999). Traditionally with these techniques, consumers are presented with coded products, and packaging, pricing, or both, may not be evaluated. Also, consumers scale liking or attribute intensities. This format, although amenable to polling large numbers of consumers, may miss unidentified key issues. Furthermore, the experience of tasting a product in a centralized location may be distinct from a home usage situation (Meilgaard et al., 1999). Qualitative consumer research methods, such as the focus group or personal interview, are designed to capture diverse aspects of consumer experiences and attitudes toward products and concepts (Meilgaard et al., 1999; Moskowitz et al., 2006). However, these techniques are prone to many factors that influence the outcomes such as moderator skill, the composition of the group, group dynamic, and personality of the panelist and the moderator guide. Consequently, the results of these qualitative studies may merely confirm what is already known and not necessarily yield true insight. Recently, an alternative protocol called quali- tative multivariate analysis (QMA) was developed to capture insights from consumers without the influence of a moderator guide and to discover the possible linkages between different and important values of products (Jacquelin Beckley, Understanding and Insight Group, Denville, NJ; personal communication, 2008). Qualitative multivariate analysis consists of home-use testing, a group discussion, and projective mapping (also called tablecloth mapping or napping techniques) with a small number of consumers (10-15). A few published studies have applied some aspects of this technique (Risvik et al., 1994, 1997; Barcenas et al., 2004; Nestrud and Lawless, 2008). To our knowledge, none have applied the entire approach (home usage, group discussion, and projective mapping) and compared findings with the results from traditional consumer research methods such as preference mapping. The objectives of this study were 1) to identify sensory properties of cottage cheese and the key drivers for consumer preference of cottage cheese, and 2) to compare traditional preference mapping results to the information gained from the smaller, more qualitative experience of QMA.

\section{MATERIALS AND METHODS}

\section{Cottage Cheeses}

Commercial cottage cheeses $(n=26)$ were collected from across the United States in 2007. Cottage cheeses were selected based on brand (national brand $=9$, regional cooperative $=5$, store brand $=11$, and private brand $=1$ ), availability, fat content (milkfat; $4 \%=9$, $2 \%=9,1 \%=4$, and $0 \%=4$ ), and curd size (small $=24$ and large $=2$ ). Cottage cheeses were received by overnight carrier on ice from the manufacturer or ordered from a local distributor. Products were examined for shipping damage and stored at $5^{\circ} \mathrm{C}$ in the dark until analysis. All products were evaluated no fewer than $21 \mathrm{~d}$ before the expiration date to minimize sensory variability associated with issues caused by the end of the shelf life.

\section{Descriptive Sensory Analysis}

Sensory testing was conducted in compliance with North Carolina State University Institutional Review Board for Human Subjects (IRB) approval. Fifty-five grams of each cottage cheese was placed into lidded 58$\mathrm{mL}$ soufflé cups with 3 -digit codes. The cottage cheeses were tempered at $12^{\circ} \mathrm{C}$ for $30 \mathrm{~min}$ and were served at this temperature with room-temperature deionized water and unsalted crackers for palate cleansing.

A trained descriptive sensory panel $(\mathrm{n}=8$ females, ages $=26-56 \mathrm{yr}$ ) with more than $1,000 \mathrm{~h}$ of experi- 
Table 1. Cottage cheese flavor and texture lexicon

\begin{tabular}{|c|c|}
\hline Term $^{1}$ & Description and reference \\
\hline Sour aromatic & Aromatic associated with short-chain fatty acids; acetic acid at $100 \mathrm{ppm}$ \\
\hline Sweet aromatic (not diacetyl) & Aromatic associated with sweet-smelling foods; Ricotta cheese \\
\hline Cooked & Aromatic associated with cooked milk, characteristic of high-temperature-processed milk; UHT skim milk \\
\hline Whey & Reminiscent of cottage cheese whey; aromatic similar to Cheddar whey \\
\hline Diacetyl & "Movie popcorn" aromatic, buttery; diacetyl at 100 ppm \\
\hline \multicolumn{2}{|r|}{ 皮 } \\
\hline Sweet & Basic taste stimulated by sugars and high-potency sweeteners \\
\hline Salty & Basic taste stimulated by sodium salts \\
\hline Sour & Basic taste stimulated by acids \\
\hline \multicolumn{2}{|r|}{ 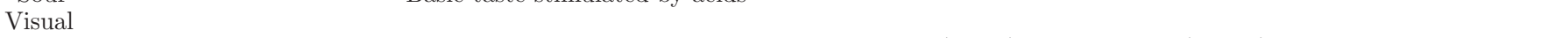 } \\
\hline Color intensity & Degree to which the sample is light, where light (white) $=0$ and dark (yellow) $=15$ \\
\hline Consistency of curd size & $\begin{array}{l}\text { Degree to which all curds are of similar size within the sample, where irregularly shaped curds }= \\
0 \text { and identically shaped curds }=15\end{array}$ \\
\hline \multicolumn{2}{|l|}{ Texture in mouth } \\
\hline Firmness & $\begin{array}{l}\text { Force required to compress the sample to the roof of the mouth using the tongue, } \\
\text { where soft curds }=0 \text { and firm curds }=15\end{array}$ \\
\hline Adhesiveness & Degree to which the sample sticks to any mouth surface, where not sticky $=0$ and very sticky $=15$ \\
\hline Smoothness of mass & $\begin{array}{l}\text { Degree to which the sample is smooth and free of lumps or grains after } 3 \text { chews, } \\
\text { where not smooth }=0 \text { and very smooth }=15\end{array}$ \\
\hline Tackiness & $\begin{array}{l}\text { How much the teeth stick together while chewing (tested by pulling teeth apart from curds) } \\
\text { where not tacky }=0 \text { and very tacky }=15\end{array}$ \\
\hline Mouthcoating & $\begin{array}{l}\text { Degree to which any sample residue remains after expectoration, where no mouthcoating }= \\
0 \text { and very mouthcoating }=15\end{array}$ \\
\hline
\end{tabular}

${ }^{1}$ Flavor intensities were scored using a 0 to 15 -point universal Spectrum intensity scale where $15=$ very high intensity of attribute and $0=$ absence of attribute (Meilgaard et al., 1999; Drake and Civille, 2003). Most dairy product flavor attributes fall between 0 and 5 on this scale (Drake et al., 2001, 2008; Drake and Civille, 2003; Wright et al., 2009). Texture and visual intensities were scored using a 0 to 15-point product-specific scale where $15=$ very high intensity of attribute and $0=$ absence of attribute (Meilgaard et al., 1999; Drake and Civille, 2003). Cottage cheese texture attributes fall between 0 and 15 on this scale.

ence each with descriptive analysis of food products and use of a 0 - to 15-point universal intensity scale (Spectrum method; Meilgaard et al., 1999; Drake and Civille, 2003) evaluated the products. The panel had six 2-h training sessions for cottage cheese to generate the lexicon for cottage cheese. During training, panelists evaluated and discussed the 26 commercial cottage cheeses and generated attributes, definitions, and references. A sensory lexicon for cottage cheese was generated and included 9, 3, 5, and 7 flavor, taste, visual, and texture attributes, respectively (Table 1). Flavor and taste attributes were evaluated using a 0- to 15 -point universal intensity scale, whereas visual and texture attributes were evaluated using a 0- to 15-point product-specific scale. The ANOVA of data collected from the last part of training indicated that the panel and panelists could consistently use the attributes to differentiate the products.

Cottage cheeses were evaluated by panelists monadically in a randomized balanced block design. Each cottage cheese was evaluated in triplicate by each panelist. Evaluations were conducted individually using Compusense Five (version 4.8, Compusense, Guelph, Ontario, Canada) in an enclosed room with positive air pressure dedicated to sensory analysis and free from external aromas, noise, and distractions. Panelists were instructed to expectorate samples after evaluation. Eight representative cottage cheeses were selected for consumer testing based on examination of descriptive panel mean attribute intensities and principal component biplots.

\section{Qualitative Consumer Testing}

Twelve self-reported consumers of cottage cheese (defined by the consumption of cottage cheese at least once per month; $\mathrm{n}=7$ females and 5 males, ages $24-35$ yr, who consumed cottage cheese a minimum of 1 time per week) were recruited to participate in the QMA study. The QMA consisted of 3 steps: home usage of 
selected products, a group interview, and a tableclothing technique.

In the home-use step, each consumer was provided with the 8 cottage cheeses (which were all 1 mo or more from expiration date) in their commercial containers to take home along with a diary. The diaries contained a colored picture of each product and the product's retail price, each on a separate blank page. Consumers were instructed to try each product at least once and if they did not like the product, they did not have to use it again. They were instructed to use the product as they typically would and as frequently as they wished. They were instructed to write down the reasons why they liked or disliked each product. The consumers kept their diaries on these products for $2 \mathrm{wk}$.

After $2 \mathrm{wk}$, the participants returned to the university with their diaries for a 4 -h group discussion. The main goal of the group discussion was to construct a value diagram representing important values for consumers (functional, emotional, price, and social values) and the linkages between the values (Moskowitz et al., 2006). The group discussion had 2 sequential steps: the "downloading" of consumer product concepts or impressions from home usage, followed by a guided group discussion. In the first 2-h session, thoughts and impressions were downloaded from each consumer in a group format. Consumers were instructed to download their opinions freely and identify important values for cottage cheese consumption. Responses were videorecorded and key insights (e.g., important values for cottage cheese consumption, sensory properties important to their purchase and consumption, and so on) were written on dry erase boards and discussed. Then, a group leader introduced each commercial product and participants discussed their impressions of each product. The downloading session lasted approximately $2 \mathrm{~h}$. Following a 15-min break, participants were then led through a group discussion format (Figure 1) to discuss and probe topics uncovered during the downloading session. Following this, and using data generated from the guided group discussion as well as the downloading session, a value diagram was generated as described by Moskowitz et al. (2006). Participants then ranked the key elements from most important to least important and the elements were used in the next step: tableclothing.

On the following day, consumers were brought in for a 5-h session. During this session, consumers conducted tableclothing (Perrin et al., 2008). The tableclothing step involved selecting important values (identified in the downloading session), constructing 2-dimensional value maps (also known as projective mapping, tableclothing, or napping), and ranking the products along the 2 dimensions selected (Risvik et al., 1994, 1997;
Barcenas et al., 2004; Nestrud and Lawless, 2008). The process started with the 2 most important values and was repeated until the panel exhausted all the important values (identified by the panel). Briefly, for the tableclothing step, commercial packages of the 8 cottage cheeses (emptied and cleaned) were presented to participants and, as a group, they were instructed to generate a projective map of their impressions of the products. The mapping exercise was conducted on a paper tablecloth $(5 \mathrm{ft} \times 5 \mathrm{ft})$ with $\mathrm{x}$ - and $\mathrm{y}$-axes taped on it. The ranked elements from the first day were used to determine the $\mathrm{x}$ and $\mathrm{y}$ coordinates. For the first map, the element that was ranked most important (sensory attributes; Table 2) was the y-axis. As a group, the participants defined the anchors for the axis with the positive y-axis defined as would eat, delicious because it is flavorful, creamy, and smooth. The negative y-axis was defined as would not eat and disgusting because it was bland and grainy. The element that was ranked next most important (brand, availability, and quality; Table 2) was the $\mathrm{x}$-axis. The positive $\mathrm{x}$-axis was defined as expensive and no free whey, whereas the negative $\mathrm{x}$-axis was defined as cheap and free whey. As a group, the participants placed each empty cottage cheese container along the $\mathrm{x}$ - and $\mathrm{y}$-axes where they thought it should fall based on the definition. Two cottage cheeses were placed very near each other if they seemed identical and 2 cottage cheeses were placed distant from one another if they seemed different. If there was controversy, the participants were allowed to place the product in different locations. The reasons for the controversy were then noted.

A second map was generated by participants in a similar manner using the third and fourth key elements generated from the previous day's discussions. For the third dimension, the positive y-axis (nutrition and ingredient) was defined as good color and the negative $\mathrm{y}$-axis was bad color. The positive $\mathrm{x}$-axis (uses) was defined as versatile and the negative $\mathrm{x}$-axis was only one use.

\section{Quantitative Consumer Evaluation}

Self-reported consumers (defined by the consumption of cottage cheese at least once per month; $\mathrm{n}=$ 110) of cottage cheese were recruited from university students, staff, and faculty through e-mails and fliers. The cottage cheeses $(n=8)$ were tested in a single session with a 1-min enforced rest between each sample. Fifty-five grams of cottage cheeses were dispensed into lidded $58-\mathrm{mL}$ soufflé cups numbered with 3 -digit codes. The cottage cheeses were served at $12^{\circ} \mathrm{C}$. Consumers $(\mathrm{n}=110)$ were provided with consent forms consistent with North Carolina State University Human Subjects 


\section{Moderator Guide for Cottage Cheese Group Discussion}

Focus area 1 - Differences between cottage cheese -20 minutes

- Do you use nonfat, lowfat (1 or $2 \%$ ), and full fat cottage cheese? Which do you use most frequently? Which do you use second most frequently? Why?

- How do nonfat, lowfat (1 or $2 \%$ ), and full fat cottage cheese differ from each other in flavor and/or texture? What do you like most about the flavor/texture of each?

- How do nonfat, lowfat (1 or $2 \%$ ), and full fat cottage cheese differ from each other in usage? Which one do you use for snacking? Which do you feed your family/friends? Which do you cook with and does it depend on the dish?

- Is there anything that would make it easier besides nonfat, lowfat (1 or $2 \%$ ), and full fat cottage cheese labels on the package that would help you select which cottage cheese to purchase?

Focus Area $2-15$ min

- What package size of cottage cheese do you use? (individual serving, $1.0 \mathrm{lb}$, or $1.5 \mathrm{lb}$ )

- What occasions do you use cottage cheese? (Breakfast, lunch, cooking, snack, etc.)

- When you purchase cottage cheese, does the curd size (large or small) matter? What is the difference between large curd cottage cheese and small curd cottage cheese

- Does the amount of free dressing/sauce (too much or too little) influence your purchase?

Focus Area 3 - Brands - 15 minutes

- What brands of cottage cheese do you most commonly purchase? Why do you purchase these over other available brands?

- I am going to name some brands and I want you to tell me your perception of them. Breakstone cottage cheese........... Darigold cottage cheese........... Daisy cottage cheese........... Nancy's cottage cheese .............Store brand cheese.............. Are these all the same in terms of quality?

Focus Area 4 - Miscellaneous - 15 minutes

- Is there anything that you would like to see changed about cottage cheese that would increase your usage of the cottage cheese? (e.g., flavors, individual serving size)

- What are the health benefits of cottage cheese? Is there anything you would like to see added to cottage cheese that would provide additional health benefits? (probiotic cultures like yogurt, omega3 , vitamins, extra calcium, extra protein)

Figure 1. Group discussion guide used in qualitative multivariate analysis. 
Table 2. Values for cottage cheese identified by consumers $(\mathrm{n}=12)$ in the qualitative multivariate analysis tableclothing step

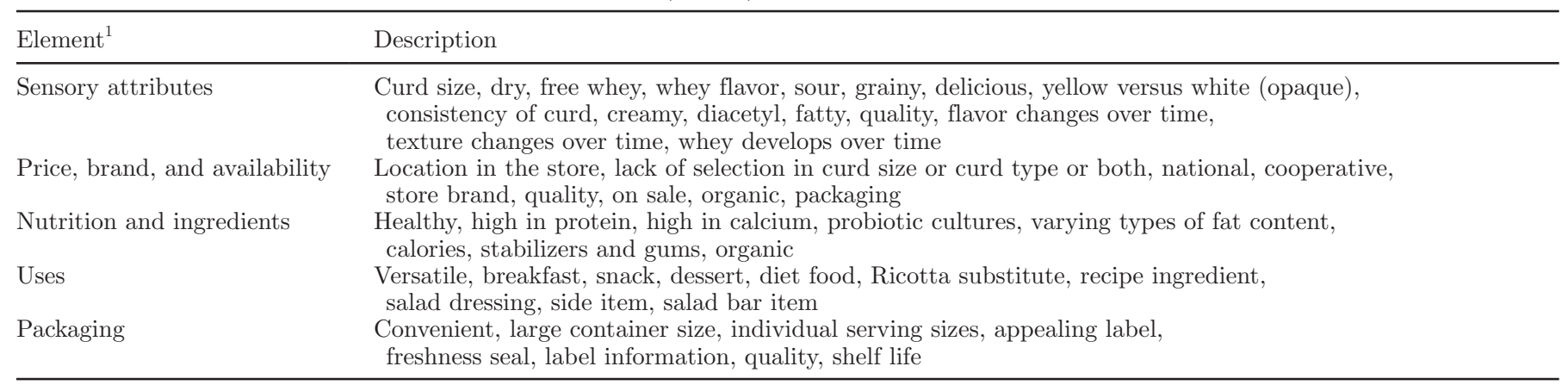

${ }^{1}$ Elements are listed in order of importance.

approval, a demographic screener, and a scoring ballot. Cottage cheeses were presented individually in a William's design. A screener form was designed for collecting demographic information and evaluating consumer decisions for cottage cheeses. The scoring ballot was used to evaluate consumer evaluations of cottage cheese for overall acceptance, appearance liking, cottage cheese flavor liking, freshness intensity, salty taste liking, sour taste liking, and texture liking, using a 9-point hedonic scale where 1 = dislike extremely or low intensity and $9=$ like extremely or high intensity. A just-about-right (JAR) scale was also used to evaluate salty taste, sour taste, curd firmness, curd size, creaminess, and free dressing. The JAR scale is a 5-point agreement scale with the center point being just about right, the left anchor being too little of the attribute, and the right anchor being too much of the attribute (Meilgaard et al., 1999). Consumers also rated purchase intent using a 5 -point scale where $1=$ definitely would not buy and $5=$ definitely would buy. Panelists were provided with deionized water and unsalted crackers for palate cleansing. Responses were collected using Compusense Five (version 4.6, Compusense). Panelists were provided with gift certificates for their participation.

\section{Statistical Analysis}

Univariate and multivariate statistical methods were used to analyze results. Descriptive and quantitative consumer data were analyzed individually and then together. An ANOVA with means separation and principal components analysis (PCA) was used to analyze the descriptive data (SAS version 9.1; SAS Institute, Cary, NC). Correlation analysis was conducted on descriptive and consumer data individually and together to determine linear relationships. Possible nonlinear relationships between consumer attributes and cheese attribute intensities were visually assessed using scatterplots. Penalty analysis was used to determine the effect of each JAR question on overall liking (XLSTAT, version 2007.7, Addinsoft, Brooklyn, NY).

Internal preference mapping was conducted on consumers means using PROC PRINQUAL of SAS (version 9.1, SAS Institute) and treatment mean scores were plotted on the resulting principal component eigenvectors. External preference mapping was performed using landscape segmentation analysis (LSA). The LSA was conducted on consumer acceptability scores using IFPrograms (release 7.9, Institute of Perception, Richmond, VA) and consumer segmentation was conducted on consumer LSA coordinates using agglomerative hierarchical clustering (AHC). Ward's method and Euclidian distance matrices were used. The resulting clusters were subjected to discriminant analysis until cross-validation correct identification of $95 \%$ or more was reached. The AHC and discriminant analysis were performed using XLSTAT version 2007.7 (Addinsoft). Two-way ANOVA of the acceptance scores with product, cluster, and product $\mathrm{x}$ cluster factors (all of them treated as fixed effects) was conducted and Tukey's honestly significant difference method was performed on any significant effect detected by the 2-way ANOVA. SPSS v.12 (SPSS Inc., Chicago, IL) was used for the ANOVA and Tukey's procedure.

\section{RESULTS}

\section{Descriptive Analysis}

Descriptive analysis results demonstrated distinguishing flavor and texture differences among the cottage cheeses (Figure 2). Four principal components (PC) explained $74 \%$ of the flavor variability. Based on the eigenvector loadings, PC1 differentiated the cottage cheeses by sour aromatic and acetaldehyde flavor and sour taste (positively loading, 26\%). Principal component $2(22 \%)$ differentiated cottage cheeses by diacetyl and milkfat flavors (loading positively) and oxidized flavor (loading negatively; Figure 2). Principal compo- 


\section{PC1 26\%}

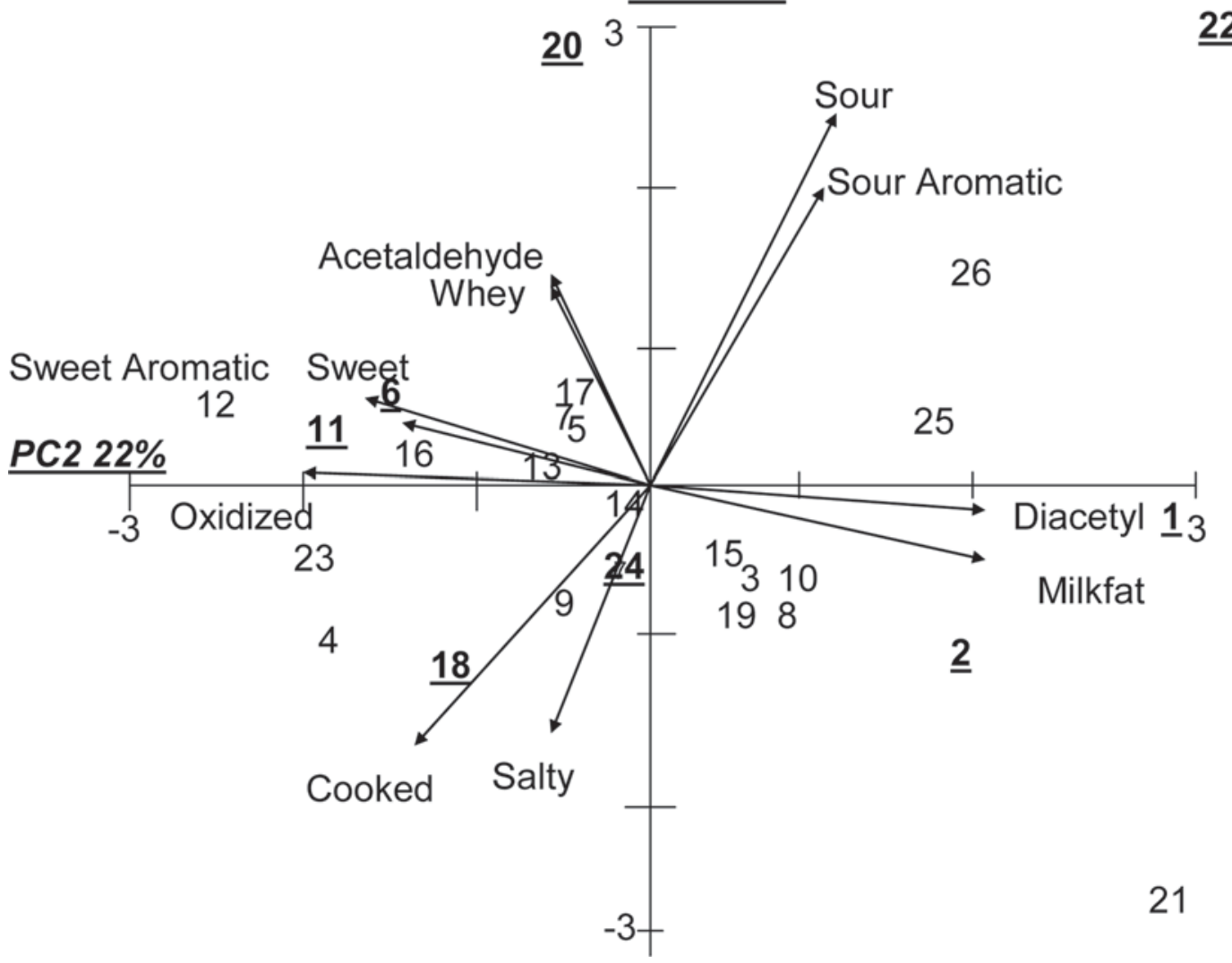

Figure 2. Principal component (PC) 1 and 2 biplot of descriptive analysis of cottage cheese flavor attributes. Cottage cheeses are represented by treatment (Trt) number (Table 1). Underlines denote cottage cheeses selected for consumer testing.

nent $3(16 \%)$ consisted of whey flavor and basic tastes of sweet and salty (loading positively) and cooked flavor (loading negatively; results not shown). Principal component $4(10 \%)$ consisted of sweet aromatic (loading positively; results not shown). Most of the cottage cheeses were characterized by cooked/milky, whey, and salty taste attributes. Milkfat flavor was dependent on the product fat content and was highest in intensity in full-fat products ( $4 \%$ milkfat). Some of the cottage cheeses displayed flavors of acetaldehyde (treatments 5 , 7, and 17), oxidized (treatments 11, 16, and 23), and diacetyl (treatments 1 and 2).

Texture attributes of cottage cheeses were also diverse (Figure 3). Four PC explained $85 \%$ of the texture variability. Based on the eigenvector loadings, PC1 differentiated cottage cheeses by mouth firmness, number of chews, opacity, and mouth coating (positively loading, 38\%), whereas PC2 (24\%) differentiated cottage cheeses by curd size and lumpiness (loading positively) and color intensity (loading negatively). Principal component 3 (15\%) consisted of adhesiveness and tackiness (loading positively) and consistency of curd (loading negatively), and PC4 (8\%) consisted of smoothness of mass (loading negatively; results not shown). There was more variability observed in the texture of the cottage cheeses than in flavor attributes, as evidenced by the range of consistency of curd, firmness of curd, amount of free dressing, and size of curd. There was variability in the flavor and texture characteristics of commercial cottage cheeses and the products chosen for consumer testing were representative of this variability (Table $3)$.

\section{QMA}

Following a 14-d home usage evaluation, cottage cheese consumers identified 5 main values of cottage cheese during a 2-h download session (Table 2). The cottage cheese consumers ranked these values from most to least important. The key values to consumers were the sensory attributes, brand and availability, nutrition, usage, and packaging. Consumer descriptors for the sensory attributes that were noted in the downloading session as positive were buttery, creamy, milkfat, fresh, and whey flavor, whereas, negative attributes were bland, too sour, grainy, not enough free dressing (dry), and 


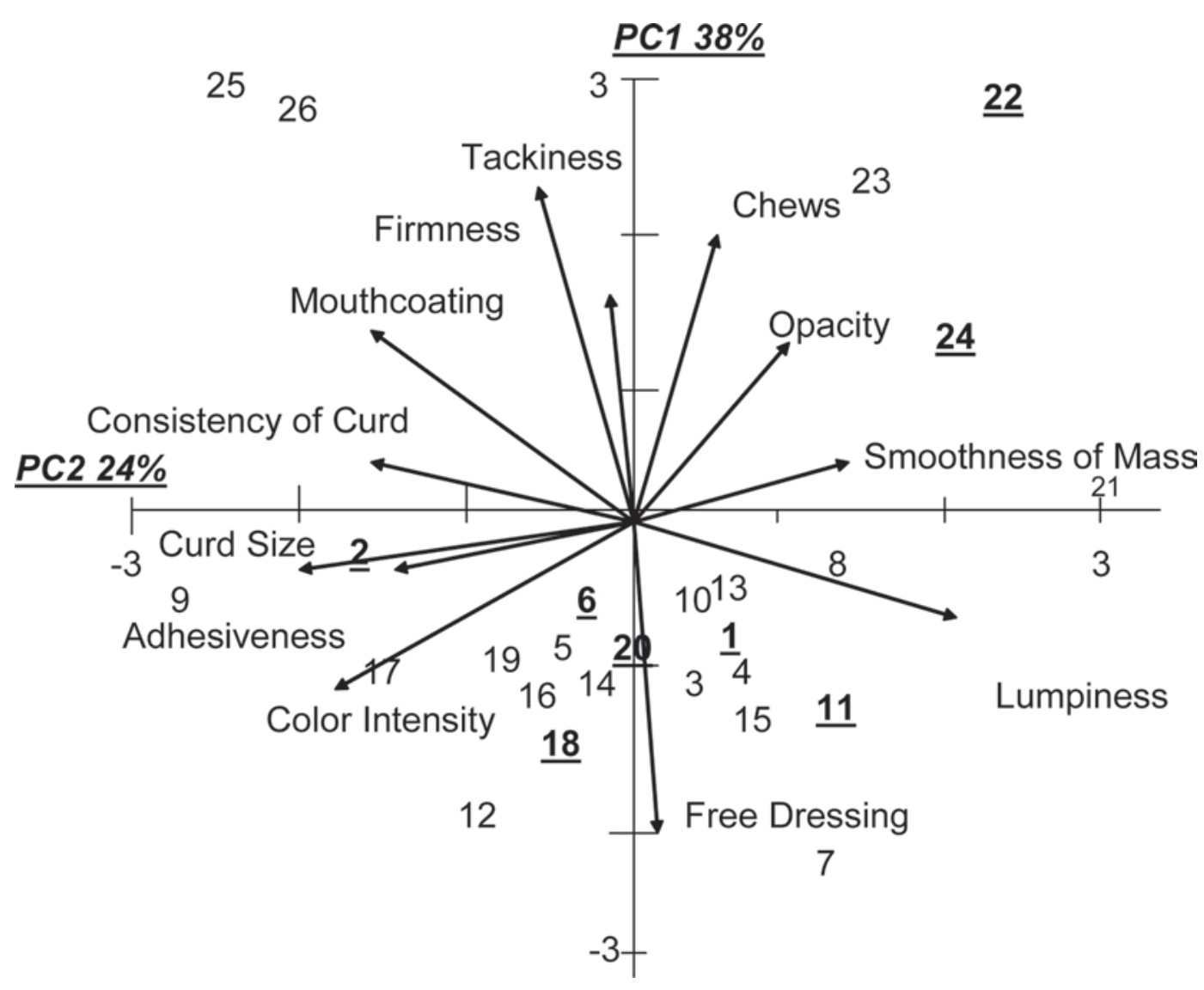

Figure 3. Principal component (PC) 1 and 2 biplot of descriptive analysis of cottage cheese texture attributes. Cottage cheeses are represented by treatment (Trt) numbers (Table 1). Underlines denote cottage cheeses selected for consumer testing.

too much free whey. The description of brand, price, and availability values noted in the download session were price (expensive or inexpensive), lack of selection, and not many brands make a large curd size. Consumers pointed out that the price of treatment 20 in their diaries was $\$ 3.99$ per pound, which was approximately $\$ 1.40$ more than other brands. Consumers wondered whether the price was a typographical error or whether treatment 20 was more expensive because this brand was advertising probiotics. Positive comments made on the nutritional value were high in protein and calcium, satiety with the full-fat versions, large selection in fat content, low in calories, some have probiotic cultures, and cottage cheese is very healthy overall. When discussing usage of cottage cheese, consumers noted very versatile, dessert, snack, side item, diet food, recipe ingredient, Ricotta substitute, salad bar item, can be used as salad dressing, and consumer can use with fruit or honey. Issues identified with packaging were unappealing package designs, would like single series option or sizes, and convenient.

In the guided discussion group, the moderator probed the issues and concepts that were brought up in the download session. Consumers (7/12) reported that they purchased $2 \%$ cottage cheese because it was what they grew up on and that it was a good compromise between fat-free and full-fat versions. Fat-free cottage cheese was purchased $(9 / 12)$ because it had fewer calories, and full-fat cottage cheese was purchased $(6 / 12)$ because it tasted good, was more filling (causing the consumer to eat less), and it was always available. Consumers $(12 / 12)$ discussed different usages with different cottage cheese fat contents. Some consumers $(3 / 12)$ felt that the full-fat version had better melting properties for cooking, some used lower fat versions because they did not have fat separation issues, and some consumers (9/12) found no big difference in cooking when using cottage cheeses of various fat contents. Some consumers $(7 / 12)$ always bought the same brand because of convenience, whereas some consumers bought various brands depending on price, availability, variety, and convenience at the grocery store.

Positive attributes of cottage cheese from the guided group discussion were consistent with the comments from the initial downloading session. These positive attributes included versatile, good snack, healthy, sa- 
Table 3. Descriptive flavor and texture attribute means for the cottage cheeses selected for consumer testing ${ }^{1}$

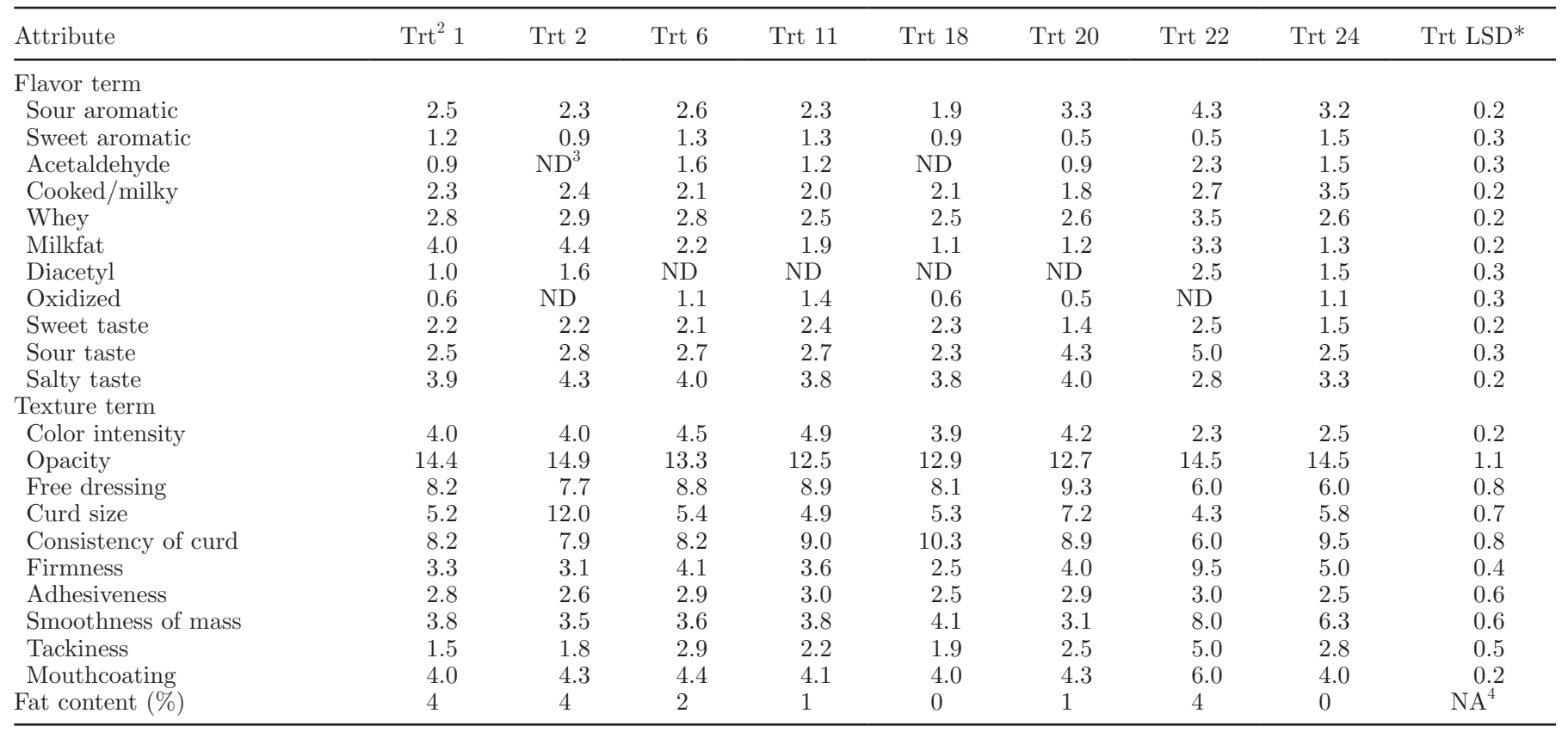

${ }^{1}$ Flavor intensities were scored using a 0 to 15 -point universal Spectrum intensity scale where $15=$ very high intensity of attribute and $0=$ absence of attribute (Meilgaard et al., 1999; Drake and Civille, 2003). Most dairy product flavor attributes fall between 0 and 5 on this scale (Drake et al., 2001, 2008; Drake and Civille, 2003; Wright et al., 2009). Texture and visual intensities were scored using a 0 to 15-point product-specific scale where $15=$ very high intensity of attribute and $0=$ absence of attribute (Meilgaard et al., 1999; Drake and Civille, 2003). Cottage cheese texture attributes fall between 0 and 15 on this scale.

${ }^{2}$ Trt $=$ treatment.

${ }^{3} \mathrm{ND}=$ not detected.

${ }^{4} \mathrm{NA}=$ not applicable.

* Means in a row that differ by the LSD are different $(P<0.05)$.

vory, convenient, filling, high protein, high calcium, and cheaper than yogurt. Negative attributes noted about cottage cheese were separation of whey, wide variability from lot to lot within brand, lots of saturated fat, boring, dry when there is not enough dressing, and no variety in packaging size. All consumers (12/12) agreed that the price was reasonable with the exception of treatment 20, which was too high. When it came to quality of product, consumers $(6 / 12)$ generally believed that store brands were lower in quality whereas national brands were higher in quality. Attributes that made consumers think lower quality were pictures of fake fruit on the package, flimsy packaging, and not stating "cottage cheese" on the label. High-quality attributes were foil taper internal lid, labeled with "farmer-owned," and stating "live cultures" on the label. Some consumers $(5 / 12)$ also believed that cottage cheese was natural when there was a visible range of curd size in the package, few ingredients were listed on the label, and no gums or thickeners were listed.

The first tablecloth map generated was based on sensory attributes and brand (Figure 4). This map showed that treatments 1,2 , and 22 were the best liked and treatment 11 was the least liked based on the sensory attributes. Treatment 1 and 2 were the least expensive products, whereas treatment 20 was the most expensive brand. There was controversy among treatments $6,18,20$, and 24 . Some of the consumers placed these treatments $(6,18,20$, and 24$)$ higher on the liking axis than other consumers. The reason for this controversy was that consumers who placed these treatments higher on the liking axis consumed cottage cheese only as an ingredient, whereas consumers who placed these treatments low on the sensory liking axis consumed cottage cheese plain. Consumers who scored these treatments $(6,18,20$, and 24) low on the y-axis did not like the flavor of these product by themselves because the cottage cheeses were bland, too sour, and had an undesirable texture (grainy or pasty). However, consumers that used cottage cheese mainly as an ingredient did not perceive or note these negative sensory attributes. The second tablecloth map generated was based on a nutritional aspect that fat content was associated with the satiety and usage (Figure 5). This map showed that treatments $1,2,22$, and 25 were best liked because of satiety, whereas treatments 11 and 18 were the least 


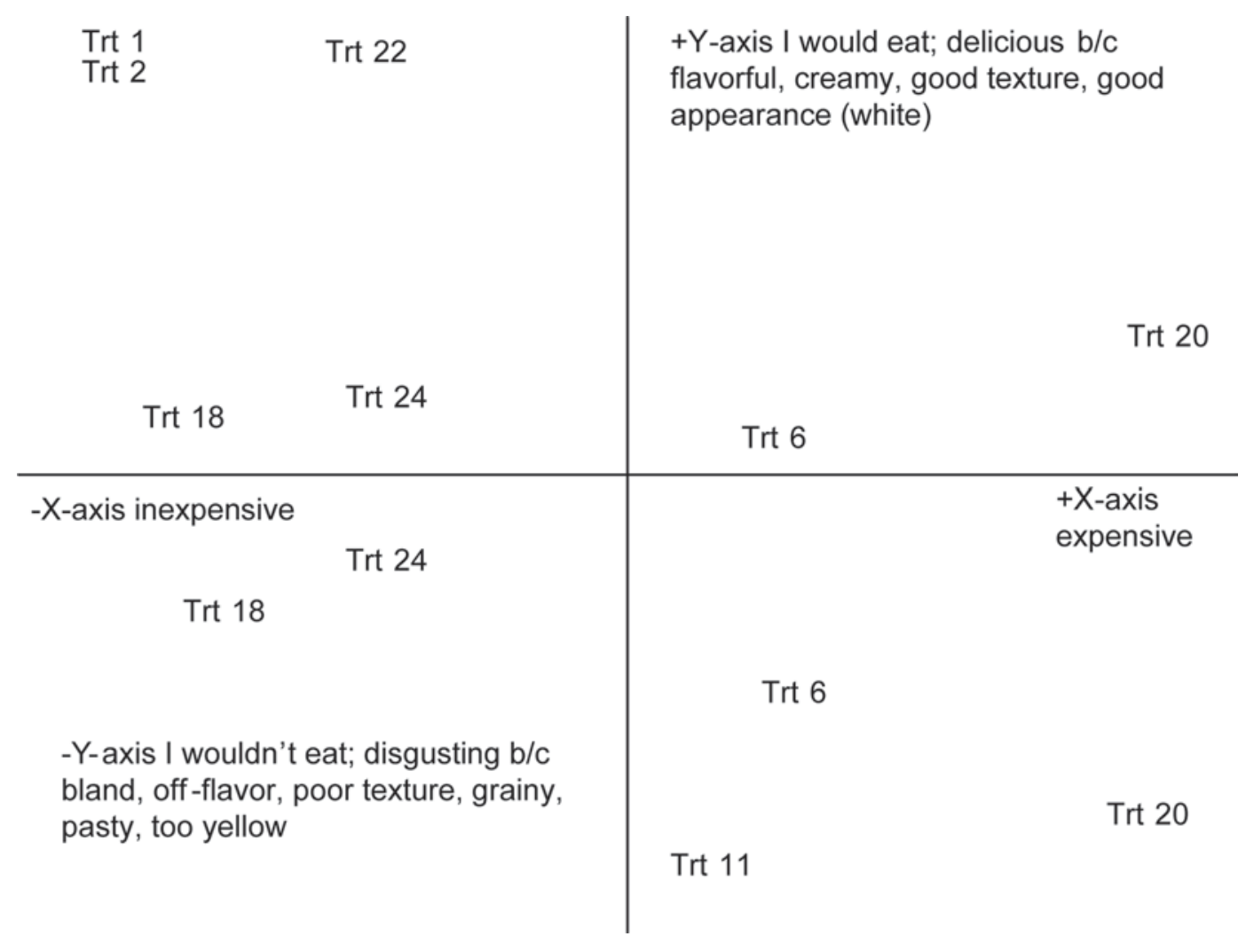

Figure 4. Perceptual map generated by consumers $(\mathrm{n}=12)$ in the qualitative multivariate analysis tableclothing step using sensory attributes and price. Duplicate treatments indicate controversial products.

liked. This was not unexpected because treatments 1 , 2,22 , and 25 were full-fat versions and treatments 11 and 18 were low-fat and nonfat, respectively. On the $\mathrm{x}$-axis, which was based on usage (either eat alone or as an ingredient), treatments $1,2,6$, and 22 were associated with eat alone, whereas treatments 6 and 11 were associated with ingredient usage. There was a lot of controversy on the x-axis about the usage of several treatments. Treatment 6 was placed on both ends of this axis. Treatment 6 was a national brand product that consumers recognized, but consumers either loved it or hated it. Treatments 20 and 24 were also controversial regarding placement on the $\mathrm{x}$-axis. These 2 treatments were split on the first tablecloth map based on sensory attributes, which influenced the placement of treatments 20 and 24 on usage.

\section{Consumer Acceptance}

Cottage cheese consumers differed in gender, age, frequency of cottage cheese consumption, types of cottage cheese consumed, usage of cottage cheese, and factors influencing choice and purchase of cottage cheese (Table 4). Differences in liking and liking attributes were documented for the cottage cheeses (Table 5). Internal preference mapping was conducted to visualize the overall consumer liking differences among the cheeses (data not shown). Two PC explained $81 \%$ of the variability. Based on the eigenvector loadings (not shown), PC1 (72\%) differentiated the cheeses by overall liking, flavor liking, freshness intensity, and purchase intent (all positively loading). Principal component 2 (9\%) differentiated by appearance liking and texture liking (loading positively) and salty and sour taste liking (loading negatively). All full-fat cottage cheeses loaded positively on PC1. Treatment 22 was closely associated with overall acceptance and purchase intent. Products with lower fat (low-fat and nonfat products) were not as closely related to liking attributes. Cottage cheeses 1,2 , and 22 , which were full-fat, scored 5.4,6.2, and 6.0, respectively, in overall acceptance, whereas cottage cheeses with lower fat contents scored between 2.5 and 4.8 in overall acceptance with the exception of treatment 24 , which was a nonfat cottage cheese scoring 5.1 in overall acceptance. Yates and Drake (2007) noted a similar trend in consumer liking with Gouda cheeses: decreasing fat content decreased consumer liking. Treatments 2 and 22 scored the highest in overall 


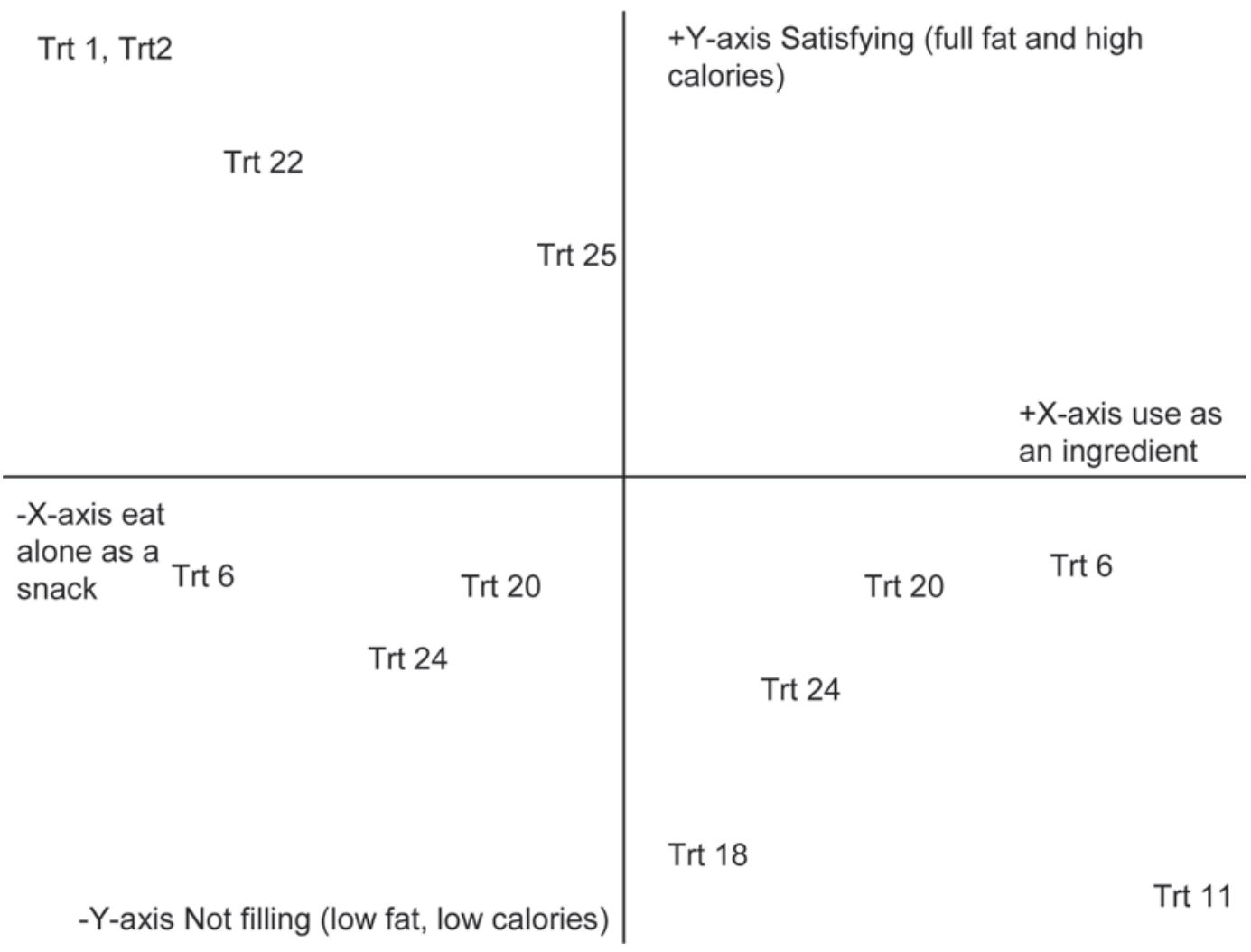

Figure 5. Perceptual map generated by consumers $(\mathrm{n}=12)$ in the qualitative multivariate analysis tableclothing step using nutrition and usage. Duplicate treatments indicate controversial products.

acceptance, freshness intensity, texture liking, and purchase intent. Treatment 20 scored the lowest in overall liking, flavor liking, freshness intensity, salty taste liking, sour taste liking, and purchase intent.

When the cottage cheeses did not meet the consumers' expectations, consumers lowered their overall liking and purchase intent scores for these cottage cheeses. Penalty analysis revealed that treatments 6,18 , and 20 were penalized in overall liking scores (on average) $1.4,3.0,1.7,1.5$, and 1.6 for too little salty taste, too much sour taste, too low in creamy texture, too small in curd size, and too much free dressing, respectively $(P<0.05$; results not shown $)$. Treatment 1 was penalized 1.1, 1.7, and 1.7 for too much salt, too much sour taste, and too little creamy mouthfeel, respectively $(P$ $<0.05$ ), whereas treatment 2 was penalized 1.4 and 1.0 for the curd size being too large and having too much free dressing, respectively $(P<0.05)$. Treatment 22 was penalized 0.9 and 1.5 for too little salty taste and too little creamy mouthfeel, respectively $(P<0.05)$. In general, consumers found most treatments to have too little salt with the exception of treatment 1 , too much free dressing except treatment 24, curd size too small except treatment 2 , too much sour taste except treat- ments 2 and 22, and not enough creamy texture except treatments 2 and 24. Several linear relationships among consumer results were determined (results not shown). Strong relationships $(P<0.0001)$ were observed between overall liking and appearance liking, flavor liking, freshness intensity, salty taste liking, sour taste liking, texture liking, and purchase intent, which were consistent with the previously discussed penalty analysis.

Landscape segmentation analysis followed by $\mathrm{AHC}$ identified 3 cottage cheese consumer preference segments and their drivers of liking (Figure 6). Segments 1, 2, and 3 contained 85, 10, and 15 consumers, respectively (Figure 6). Diacetyl and milkfat flavors, smoothness of mass, and mouthcoating were identified as drivers of liking for segment 1 . These drivers of liking were also consistent with the key desirable attributes of cottage cheese identified by consumers in the QMA study. Because the QMA study utilized only consumers, the key sensory attributes identified by QMA were expressed in consumer language: buttery flavor (diacetyl and milkfat), creaminess (milkfat flavor, mouthcoating), and smoothness (smoothness of mass). The large number of consumers in segment 1 suggests homogenous consumer liking for cottage cheese. In segment 1 (Figure 6), treat- 
Table 4. Demographic information and consumption characteristics of cottage cheese consumers $(\mathrm{n}=110)$

\begin{tabular}{|c|c|}
\hline Item & Consumers (\%) \\
\hline \multicolumn{2}{|l|}{ Gender } \\
\hline Male & 30 \\
\hline Female & 70 \\
\hline \multicolumn{2}{|l|}{ Age group } \\
\hline $19-24$ yr & 28 \\
\hline $25-30 \mathrm{yr}$ & 25 \\
\hline $31-35$ yr & 6 \\
\hline $36-45$ yr & 13 \\
\hline $46-55 \mathrm{yr}$ & 18 \\
\hline$>55$ yr & 10 \\
\hline \multicolumn{2}{|c|}{ Frequency of cottage cheese consumption } \\
\hline$<1$ time $/$ mo & 58 \\
\hline $2-4$ times $/ \mathrm{mo}$ & 27 \\
\hline$>1$ time/wk & 15 \\
\hline \multicolumn{2}{|c|}{ Type of cottage cheese consumed ${ }^{1}$} \\
\hline Fat-free ( $0 \%$ fat) & 22 \\
\hline Low-fat ( $1 \%$ fat) & 49 \\
\hline Reduced-fat (2\% fat) & 55 \\
\hline Full-fat ( $4 \%$ fat) & 40 \\
\hline \multicolumn{2}{|l|}{ Usage of cottage cheese ${ }^{1}$} \\
\hline Snack & 54 \\
\hline On a salad & 45 \\
\hline With fruit & 55 \\
\hline Breakfast & 20 \\
\hline Other & 27 \\
\hline \multicolumn{2}{|l|}{ Factor influencing purchase ${ }^{1}$} \\
\hline Price & 66 \\
\hline Availability & 34 \\
\hline Brand & 40 \\
\hline Health & 37 \\
\hline Flavor & 73 \\
\hline Packaging & 15 \\
\hline Ingredient & 5 \\
\hline \multicolumn{2}{|l|}{ Brand of cottage cheese $\mathrm{e}^{1,2}$} \\
\hline Breakstone & 47 \\
\hline Friendship & 2 \\
\hline Organic Valley & 15 \\
\hline Light n’ Lively & 16 \\
\hline Lactaid & 3 \\
\hline Land O'Lakes & 23 \\
\hline Food Lion store brand & 32 \\
\hline Harris Teeter store brand & 36 \\
\hline Kroger store brand & 26 \\
\hline Other & 15 \\
\hline
\end{tabular}

${ }^{1}$ Consumers were allowed to choose more than 1 category; therefore, category percentages do not add up to 100.

${ }^{2}$ Breakstone: Kraft Foods, Glenview, IL; Friendship: Friendship Dairies, Friendship, NY; Organic Valley: Organic Valley, La Farge, WI; Light n' Lively: Kraft Foods, Glenview, IL; Lactaid: HP Hood LLC, Chelsea, MA; Land O'Lakes: Land O'Lakes Inc., St. Paul, MN; Food Lion store brand: Food Lion LLC, Salisburg, NC; Harris Teeter store brand: Harris Teeter, Matthews, NC; Kroger store brand: The Kroger Co., Cincinnati, $\mathrm{OH}$. Brands are those that customers purchase regularly. Only brand names (not manufacturers) were shown on survey screen.

ments 2 and 22 scored the highest in overall liking with means of 5.8 and 6.0 , respectively, whereas treatment 20 scored the lowest in overall liking with a mean score of 3.0. It is important to note that treatment 20 scored the lowest in overall liking for all 3 segments. This cottage cheese was characterized by descriptive analysis as very sour, low in milkfat flavor, and a high number of shattered curds. Although segments 2 and 3 were small, these results suggest the potential for special niches for cottage cheese. Segment 2 consumers liked consistent curd size, cooked flavor, and salty taste in cottage cheese, and segment 3 consumers liked more free dressing and opaque color intensity.

\section{DISCUSSION}

Very little previous work has documented differences in commercial cottage cheese flavor and texture profiles. One study by Antinone et al. (1994) evaluated the detection threshold and consumer acceptance of diacetyl in full-fat cottage cheese and found that diacetyl could be detected at $0.2 \mathrm{ppm}$ in cottage cheese. Consumer aroma, flavor, and overall liking attributes of cottage cheese increased as a function of concentration of diacetyl (0.0 to $4.0 \mathrm{ppm}$ ), with the mean flavor score peaking at $1.0 \mathrm{ppm}$. Our study also found an increase in overall liking with cottage cheeses that had a diacetyl flavor compared with those that did not. The dairy judging criteria for cottage cheese has been used as the gold standard for evaluating the quality of cottage cheese for the past 50 years. Dairy judging criteria of cottage cheese is broken down into 3 areas: flavor, body and texture, and appearance and color defects (Bodyfelt and Potter, 2009). The flavor and texture lexicon developed in this paper addresses some of the terms used in the dairy judging criteria. However, the terms used in the dairy judging criteria are not a language that consumers recognize, nor are the positive and negative judging attributes consistent with consumer likes and dislikes. For instance, high diacetyl or high salt may be a defect according to the dairy judging criteria, but to consumers, high intensities of these attributes may make cottage cheese more appealing. Our flavor and texture lexicon provides a more descriptive and powerful tool for understanding consumer liking of cottage cheese.

Qualitative multivariate analysis is a relatively new protocol and has been used mainly in industry settings. Many techniques such as focus groups, group discussion, projective mapping, and the napping procedure have been used alone to allow consumers to express their experiences and attitudes, especially the last 2 techniques, which allow consumers to express their perceptual similarities or differences among a group of products on a 2-dimensional plane (Risvik et al., 1994; Pages, 2005; Nestrud and Lawless, 2008). Several studies have compared one of these single techniques to other techniques. Risvik et al. (1994) compared 3 methods (conventional profiling, dissimilarity profiling, and a new technique called projective mapping) that allowed consumers to evaluate molded chocolate. These investigators found that projective mapping gave 
Table 5. Consumer liking attribute means for cottage cheeses $(\mathrm{n}=110$ consumers $)$

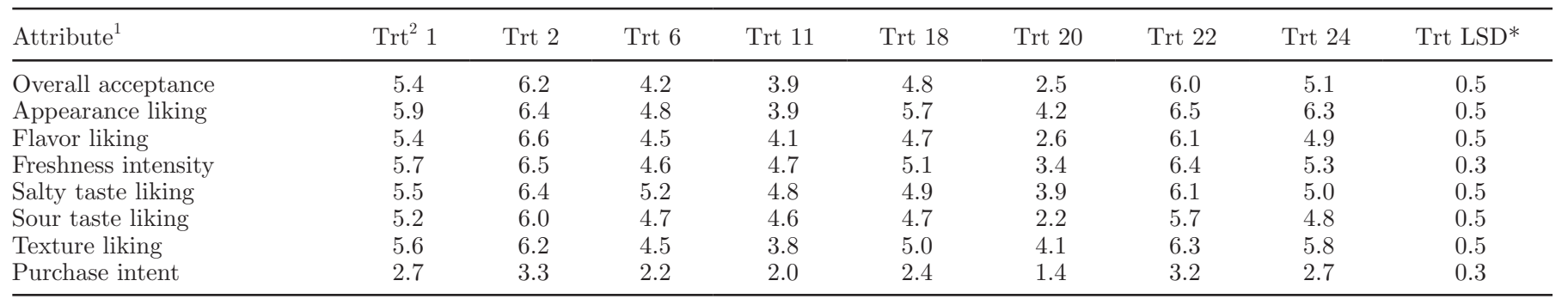

${ }^{1}$ Attributes were scored on a 9-point hedonic scale where $1=$ dislike extremely and $9=$ like extremely. Purchase intent was scored on a 5 -point scale where $1=$ definitely would not purchase and $5=$ definitely would purchase.

${ }^{2}$ Trt $=$ treatment.

* Means in a row that differ by more than the LSD are different $(P<0.05)$.

similar maps as conventional profiling and dissimilarity profiling, but with repeated trials the projective mapping was more consistent than the other 2 methods. More recent studies have shown similar configurations between trained panelists or experts and consumers (Barcenas et al., 2004; Nestrud and Lawless, 2008), suggesting that projective mapping may be a good tool to link consumer data and sensory analysis (Risvik et al., 1994). Pages (2005) introduced the napping procedure, which is a type of perceptual map, to evaluate wines from the Loire valley using naïve consumers and was able to link the results to descriptive profiles of wine experts. None of these studies have compared consumer projective maps with consumer preference maps.

The parts that make QMA different from other projective mapping techniques are the download session (identify elements), the subsequent group discussion, and the tablecloth mapping exercise. Qualitative mul-

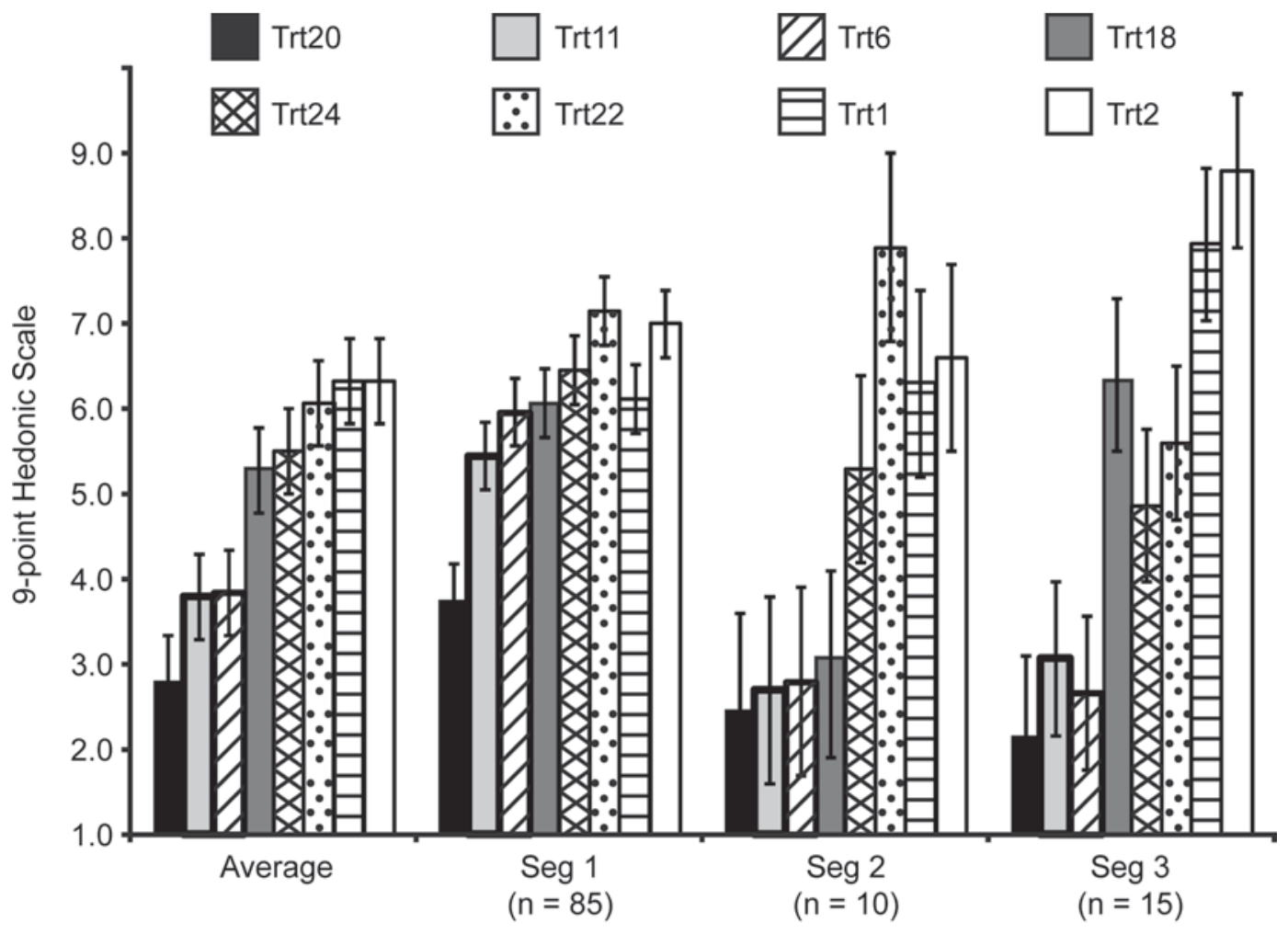

Consumer Segments

Figure 6. Cottage cheeses averaged across all consumers and then separated by segment. Mean overall liking scores for each consumer segment. Treatment numbers refer to cottage cheeses. Bars indicate 95\% confidence intervals of the mean. Products were scored on a 9-point hedonic scale where $1=$ dislike extremely and $9=$ like extremely. 
tivariate analysis in itself is a protocol (a collection of techniques conducted in sequence to reach a certain goal) and it brings advantages from many techniques together. Through QMA, researchers may discover insights about the products directly from consumers without any predetermined agenda and with ecological relevancy. The download session allows consumers to freely express their experience of products under their actual usage condition (i.e., home use condition). The group discussion is guided by the information from the download session (not a predetermined agenda) and only important matters identified in the download session are discussed. Finally, the selected factors of the product that are important to consumers can be used in creating the perceptual map using the tablecloth technique.

In this study, problems that were documented in the past with cottage cheese - bland, lacks flavor (Antinone et al., 1994), diet food (Reiter, 1993), inconsistency in product quality, decreased curd-to-dressing ratio, and inconvenient packaging (Honer, 1990; Reiter, 1993; Bodyfelt and Potter, 2009)-were also documented in the download session of the QMA study. In 1999, cottage cheese started to make a comeback with the addition of fruit purée (Berry, 1999) and the targeting of products containing prebiotics and probiotics (Ramirez, 2007), and consumers did mention these items during our download session. The downloading process identified different consumer usages for cottage cheese that not all consumers had heard about. From this session, one useful idea might be to incorporate recipes into the label of the cottage cheese packaging. Consumers also discussed convenience, single-serve portions, and more availability of prepackaged flavors like cottage cheese with fruit or savory flavors.

Overall liking of the product was (not surprisingly) identified by QMA as an important factor to cottage cheese consumption. Comparing the perceptual map generated by QMA along the overall liking axis (Figure 4) to the results from LSA and AHC (a traditional preference mapping technique; Figure 6), the results were similar in liking directions for the cottage cheeses, with treatments 1,2 , and 22 scoring the highest, treatments 18 and 24 scoring in the middle, and treatments 6,11 , and 20 scoring the lowest in overall liking. It is worth noting that LSA followed by AHC revealed that cottage cheese consumers were quite homogenous, with the majority of consumers falling in the middle of segment 1. Therefore, the results from QMA (with a smaller sample size of 12 consumers) agreed quite well with the results from LSA and AHC. This result may not be possible in the case of highly segmented market products.
This research demonstrates that cottage cheese consumers see cottage cheese as a very healthy and versatile product. However, because of the lack of advertisement, many consumers have forgotten this product. Cottage cheese manufacturers need to advertise cottage cheese to help get the product back in people's minds and help consumers with ideas on how to use the product. In today's world, the internet could easily be used to distribute recipes that use cottage cheese. Manufacturers also need to decide whether they are making cottage cheese for the masses or for specialty niches. Depending on the target consumer, the most appealing flavor profile of cottage cheese will be slightly different. Furthermore, in today's busy world, everyone is on the go; manufacturers need to think about portability, single servings, and premade flavors that target savory or sweet flavors such as chives or jam.

\section{CONCLUSIONS}

Qualitative multivariate analysis was very helpful in evaluating consumer preference and perception of cottage cheese because consumers were able to use the product in its actual context (i.e., the results are more ecologically relevant). This allowed better understanding of product applications and differentiation of product preferences because consumers used the product in different applications, provided feedback with an understanding of controversial issues with certain cottage cheeses, and provided information on more than sensory attributes. Traditional preference mapping provided a quantitative level of understanding, focusing on sensory attributes and the relationship between the descriptive sensory attributes and predetermined key product indicators, especially overall liking. Traditional preference mapping is very effective for product development when a key product indicator is identified; however, it was not designed to provide insights regarding consumer behavior and the interaction between other relevant factors. The products are tested blind and, most of the time, consumers consume the products under unnatural conditions (at a laboratory, with a specified amount, standardized serving protocol, and so on) without any additional relevant information such as price, brand, and packaging. Therefore, for holistic understanding of product experience, QMA is a better protocol. Meanwhile, preference mapping provides a better understanding of the sensory experience of products. The choice of using one method or another is dependent on several factors such as time, budget, number of products, type of products, and context. The use of QMA before preference mapping would help companies to make better assumptions to warrant 
the success of the big investment of preference mapping. Similar directions of liking of cottage cheese were identified using either traditional preference mapping or QMA. The drivers of liking for cottage cheese were buttery flavor (diacetyl and milkfat flavors), creaminess (milkfat flavor and mouthcoating), and smoothness of texture (smoothness of mass). These results can help the cottage cheese industry expand the product line or understand where the industry needs to focus to help revive cottage cheese sales.

\section{ACKNOWLEDGMENTS}

This study was funded in part by Dairy Management, Inc. (Rosemont, IL). Manuscript FSR 09-32 of the Department of Food, Bioprocessing, and Nutritional Sciences, North Carolina State University (Raleigh). The use of trade names does not imply endorsement, nor does it imply lack of endorsement of those not mentioned.

\section{REFERENCES}

Anonymous. 2006. USDA dairy product 2006 summary. http://future. aae.wisco.edu/tab/production.html\#68 Accessed Apr. 4, 2008.

Antinone, M. J., H. T. Lawless, R. A. Ledford, and M. Johnston. 1994. Diacetyl as a flavor component in full fat cottage cheese. J. Food Sci. 59:38-42.

Barcenas, P., F. J. Perez Elortondo, and M. Albisu. 2004. Projective mapping in sensory analysis of ewes milk cheeses: A study on consumers and trained panel performance. Food Res. Int. 37:723729 .

Berry, D. 1999. Cultured products: Data shows the cultured category growing, with cottage cheese the shining star. http://findarticles. com/p/articles/mi_m3301/is_5_100/ai_54774109 Accessed Dec. 19,2008 .

Bodyfelt, F. W., and D. Potter. 2009. Sensory evaluation of creamed cottage cheese. Pages 167-190 in The Sensory Evaluation of Dairy Products. S. Clark, M. Costello, M. A. Drake, and F. Bodyfelt, ed. Van Nostrand Reinhold, New York, NY.

Code of Federal Regulations. 2004. Code of Federal Regulations, title 21. Vol. 2: Food and drugs. U.S. Government Printing Office. http://www.access.gpo.gov/cgi-bin/cfrassemble.cgi?title=200721 Accessed Dec. 4, 2007.

Demott, B. J., J. P. Hitchcock, and O. G. Sanders. 1984. Sodium concentration of selected dairy products and acceptability of a sodium substitute in cottage cheese. J. Dairy Sci. 67:1539-1543.

Drake, M. A., and G. V. Civille. 2003. Flavor lexicons. Comprehensive Rev. Food Sci. Food Safety 2:33-40.

Drake, M. A., S. C. McIngvale, P. D. Gerard, K. R. Cadwallader, and G. V. Civille. 2001. Development of a descriptive language for cheddar cheese. J. Food Sci. 66:1422-1427.
Drake, M. A., M. Yates, and P. D. Gerard. 2008. Determination of regional flavor differences in U.S. Cheddar cheeses aged for six months or longer. J. Food Sci. 73:199-208.

Honer, C. 1990. Can cottage cheese recover? A variety of factors contribute to 20 years of declining consumption. (Plant operations.) http://findarticles.com/p/articles/mi_m3301/is_n7_ v91/ai_9373579 Accessed Dec. 18, 2008.

Krause, A. J., K. Lopetcharat, and M. A. Drake. 2007. Identification of the characteristics that drive consumer liking of butter. J. Dairy Sci. 90:2091-2102.

Meilgaard, M., G. V. Civille, and B. T. Carr. 1999. Selection and training of panel members. Pages 135-183 in Sensory Evaluation Techniques. 2nd ed. CRC Press, Boca Raton, FL.

Moskowitz, H. R., J. H. Beckley, and A. V. A. Resurreccion. 2006. Understanding consumers' and customers' needs - The growth engine. Pages 37-68 in Sensory and Consumer Research in Food Product Design and Development. H. R. Moskowitz, J. H. Beckley, and A. V. A. Resurreccion, ed. Blackwell Publishing, Ames, IA.

Nestrud, M. A., and H. T. Lawless. 2008. Perceptual mapping of citrus juices using projective mapping and profiling data from culinary professionals and consumers. Food Qual. Prefer. 19:431-438.

Pages, J. 2005. Collection and analysis of perceived product interdistances using multiple factor analysis: Application to the study of 10 white wines from the Loire Valley. Food Qual. Prefer. 16:642-649.

Perrin, L., R. Symoneaux, I. Maitre, C. Asselin, F. Jourjon, and J. Pages. 2008. Comparison of three sensory methods for use with the Napping ${ }^{\circledR}$ procedure: Case of ten wines from Loire valley. Food Qual. Prefer. 19:1-11.

Ramirez, J. C. 2007. Cottage on the cusp. http://www.dairyfoods. com/Archives_Davinci?article=1169 Accessed Mar. 25, 2009

Reiter, J. 1993. Saving a category-Cottage cheese. http://findarticles. com/p/articles/mi_m3301/is_n3_v94/ai_14080734 Accessed Dec. $18,2008$.

Risvik, E., J. A. McEwan, J. S. Colwill, R. Rogers, and D. H. Lyon. 1994. Projective mapping: A tool for sensory analysis and consumer research. Food Qual. Prefer. 5:263-265.

Risvik, E., J. A. McEwan, and M. Rodbotten. 1997. Evaluation of sensory profiling and projective mapping data. Food Qual. Prefer. 8:63-71.

Singh, T. K., M. A. Drake, and K. B. Cadwallader. 2003. Flavor of Cheddar cheese: A chemical and sensory perspective. Comp. Rev. Food Sci. Food Safety 2:139-162.

Walstra, P., T. J. Geurts, A. Noomen, A. Jellema, and M. A. J. S. van Boekel. 1999. Cheese ripening and properties. Pages 601-636 in Dairy Technology. P. Walstra, T. J. Geurts, A. Noomen, A. Jellema, and M. A. J. S. van Boekel, ed. Marcel Dekker Inc., New York, NY

Wright, B., S. E. Zevchak, J. M. Wright, and M. A. Drake. 2009. The impact of agglomeration and storage on flavor and flavor stability of whey protein concentrate $80 \%$ and whey protein isolate. J Food Sci. 74:17-29.

Yates, M. D., and M. A. Drake. 2007. Texture properties of Gouda cheese. J. Sens. Stud. 22:493-506.

Young, N. D., M. A. Drake, K. Lopetcharat, and M. R. McDaniels. 2004. Preference mapping of Cheddar cheese with varying maturity levels. J. Dairy Sci. 87:11-19. 